\title{
Discussion on Method of Improving the Accuracy of Electric Energy Metering
}

\author{
Yanhua Ning ${ }^{1}$, Xinru Cai ${ }^{1}$ \\ ${ }^{1}$ Jiangxi Vocational and Technical College of Electricity, Nanchang, 330032, China
}

Keywords: Electric energy metering; accuracy; method

\begin{abstract}
With the progress of electric power technology in China, the electric power enterprises pay more and more attention to the accuracy of electric energy metering because it cannot only affect the efficient utilization of electric power resources, but also affect the economic benefits of electric power enterprises. In the power system, the electric energy meter is a special instrument for electric energy metering. As the accuracy of electric energy meter determines the economic benefit of electric power enterprise, therefore, the problems in the electric energy metering must be found and the effective solution must be taken.
\end{abstract}

\section{Introduction}

The electric energy metering device is an important equipment of electric energy metering, by which the users and power supply enterprises can accurately grasp the information of electric energy metering. For recent years, China's economy has developed rapidly, and the electric power plays an indispensable role in people's life, work and learning. In addition, with the continuous increase of people's material life, and increasingly complete household appliances, the electric consumption increases greatly, so the accurate electric energy metering has become an important factor that affects the national economic growth and social stability. Thus, it is required to deeply analyze the problems of electric energy metering device, find the errors and take the effective solution to improve the accuracy of electric energy metering

\section{Role and importance of electric energy metering device}

\section{Role of electric energy metering device}

The electric energy metering device is an important part of power system and the electric energy meter is the most important part of electric energy metering device and also the indispensable element of electric energy metering. The accurate electric energy metering and normal operation of electric energy meter can provide effective basis for the transfer of power and the settlement of power trade. The operation of power system includes the power generation, power supply, power utilization and other links and these links need other metering device to metering the volume of power generation, power supply, power consumption and power sales. The accurate electric energy metering can service the electric energy calculation and also is an important basis for compiling the production plan and ensuring the reasonable economic calculation, especially in the modern agricultural production, chemical production and commercial trade, in which it is allowed to scientifically save the resources, compile the reasonable power consumption quota and improve the management efficiency only by correctly mastering the power consumption.

\section{Importance of electric energy metering}

The electric energy meter has a history of 100 years since its invention. As the electric energy metering device, its scientific level and performance are directly related to the intelligent management, so the structure and performance of electric energy meter are perfected continuously with the increase of the electric management level. At present,with the continuous maturity and development of Chinese market economy, the market competition faced by electric power enterprises becomes more and more fierce and how to gain advantage in the fierce competition has become a key issue in the study of electric power enterprise. To improve the economic benefits of electric power enterprises, it is a must to reduce the production cost and energy loss; meanwhile, it 
is also required to improve the management and marketing level, improve the metering, provide reliable electric energy metering data, strengthen the effective management of power calculation, and adopt the accurate, reliable and systematic electric energy metering mode. The accurate electric energy metering is directly related to the interests of power plant, power supply enterprises and users. With the deepening of informatization and industrialization, the electric energy has become an indispensable resource in Chinese economic development and people's daily life and learning and the accurate electric energy metering has become a social requirement. The improvement of the accuracy of electric energy metering if of importance significance for all aspects of the society. Since the reform and opening up, China has gradually transformed from planned economy to the market economy and the power system is also of reform oriented on the market economy, at which the electric energy metering technology has developed greatly, especially in terms of the completeness and accuracy of electric energy metering. The rapid economic development promotes the development of industrial units and the changes of people's lifestyle and life concept, thus leading to the severe power fluctuation, greater and greater difference of power consumption peak valley and increasing error of electric energy metering. Thus, the improvement of the accuracy of electric energy metering is of great significance.

\section{Reason for error of electric energy metering}

The error of electric energy metering device is caused by multiple factors and the error is also the result of the combined action of multiple aspects. Therefore, in practices, it is required to carry on the analysis according to the causes of error and then suit the remedy to the case, so as to reduce the error comprehensively and improve the accuracy of electric energy metering. For the electric energy metering device, the error is caused by four aspects. First, by the error of electric energy meter. The error of electric energy meter is one of the main causes of the error of electric energy metering and mainly includes three cases: error of load characteristic of electric energy meter, error caused by improper use of electric energy meter and production error of electric energy meter. The error of load characteristic of electric energy meter refers to the metering error of electric energy meter caused by load current and power fluctuation. The load error of electric energy meter is great under the low load conditions. The error caused by improper use of electric energy meter mainly refers to the metering error of electric energy meter caused by disconnection or wiring error of electric energy meter. The production error of electric energy meter refers to the metering error of electric energy meter because the electric energy meter manufacturer fails to produce the electric energy meter strictly in accordance with the relevant national standards. Second, by the error of transformer. The error of transform mainly has two reasons: one is that the transformer is of low accuracy and the other is that the electric energy metering lacks of special secondary winding of transformer. The transformer level of power plant and substation in China is low earlier, which is only level 0.5 generally, greatly differing from the current provisions. According to the regulation of Chinese standard, it is guaranteed only when the transformer accuracy level is between $25 \%$ and $100 \%$ and the too big or small load will lead to the error of transformer. When the electric energy meter is connected to the circuit with the current transformer and a primary current flows through the primary winding of current transformer, the secondary winding will produce the induced electromotive force, thus leading to the consumption of partial current, because of which the error of current transformer generates. Third, by the step-down of secondary wire. Before the input end of electric energy meter and the output end of voltage transformer, there are wire resistance, relay contact, fuse and contact resistance of relevant instrument. When the current flows through the wire between them, a step-down will generate. For the electric energy meter, the phase shift and step-down on the circuit will cause an additional error to the voltage transformer, finally leading to the metering error. Finally, by the external human factors. With the progress of social production and life, the use of electric energy metering system has become a sign of the progress of electric power enterprises. However, as the cost and investment for using the electric energy metering system is great and the enterprise can obtain the small benefits, so the leader and administrator of electric power enterprise fail to pay much attention to the use of electric power metering system, the 
electric power department fails to conduct effective management of metering staff, many new staff engaging in the metering do not have professional occupational training and the metering staff lack of necessary experience and professional skills. It is these reasons that lead to the fact that the power metering staff cannot effectively master the metering conditions of enterprises. If the metering staff lack of professional metering skills, there may be various unreasonable and unscientific phenomena in the use of metering device, thus leading to the error of electric power measurement. In addition, some staff are not serious upon metering, thus leading to the decrease of the accuracy of electric energy metering.

\section{Method of improving the accuracy of electric energy metering}

\section{Choose the up-to-stand and high-precision electric energy meter}

The most effective and fundamental measure to improve the accuracy of electric energy metering is to use the standard, multi-functional, high-precision and strong-stability electric energy meter. In the actual metering process, the model, current, voltage and accuracy level of electric energy meter must be chosen according to the use requirements and relevant provisions. With the continuous progress of electronic technology, the electric energy meter has more and more functions and increasingly mature technology, so the error is decreased gradually. The multi-functional electronic electric energy meter has many advantages: in the metering process, the meter can be of positive and negative active and inactive action and some auxiliary functions, such as positive and negative energy accumulation. Compared with the ordinary electric energy meter, the multi-functional electric energy meter is of strong overload ability and less power consumption. In the actual operation, the low-load operation of big-load current meter will certainly increase the error, thus, the wide-load S-level electronic electric energy meter can be chosen, which can effectively reduce the error and improve the accuracy of electric energy metering.

\section{Correctly choose the transformer and secondary circuit}

The error caused by transformer and secondary circuit is one of the main part of electric energy metering error. To improve the accuracy of electric energy metering, the measuring error caused by transformer and secondary circuit must be reduced. The determination of the rated primary current of current transformer should make the load and current in the actual operation reach $60 \%$ of rated current, but not less than $30 \%$ of rated value. The rated load of transformer shall be controlled within 1.5-3 times of actual load and the minimum rated capacity of transformer shall not be less than the actual load and the maximum rated capacity shall not be more than 4 times of actual load. The secondary load of transformer should be confirmed according to the actual situation. The rated secondary load power factor of current transformer should be between 0.8 and 1.0 and the rated secondary load power factor of voltage transformer should be 0.8. During the selection of the cross section of secondary loop conductor, attention should be paid to the following problems: the cross-section area of connecting wire should be confirmed according to the actual load of secondary circuit of current transformer, which shall not be less than $4.0 \mathrm{~mm}^{2}$. For the secondary voltage circuit, the cross-section area of connecting wire should be confirmed according to the allowable voltage, which shall not be more than $4.0 \mathrm{~mm}^{2}$. If the cross-section area of wire, which is more than $4.0 \mathrm{~mm}^{2}$, is required after calculation, the cross section can be increased in the form of parallel laying of cables, the reasonable matching problem of transformer should be considered and the ratio error symbol of current and volage transformer connected with the same element of electric energy meter should be different as far as possible, with approaching numerical value and the angular difference symbol should be same, with approaching numerical value. By reasonably choosing the transformer and secondary circuit, the error of electric energy metering device can be further reduced to improve the improve the accuracy of electric energy metering.

\section{Establish effective rules and regulations}

For the electric energy metering, the effective, reasonable and scientific rules and regulations, such as drawing management and approval system, initial installation filing system of metering device, new installation acceptance system, regular shifting system, failure repair system, spot detection system, management and maintenance system and metering instrument scrapping system, must be 
established. The first assembly of electric energy meter and the replacement of electric energy metering device must have detailed and clear information, such as the model and function of electric energy meter, which are beneficial to the management of electric energy metering device. Before the replacement of electric energy metering device, the professional metering staff must conduct appraisal first. During replacement, the staff must strictly conform to the appraisal report and immediately record the events as required to provide references for the future checking and repair. The relevant staff must regularly check and file the electric energy consumption, electric charges and operation conditions of metering device for the convenience of subsequent repair. For some electric power enterprises, although the right of use of electric energy meter and transformer is acquired in the form of mortgage, which is also allowed by the law, the enterprises still have to conduct regular inspection of these devices to avoid any failure and any damage of device to affect the power consumption safety and economic interests of enterprises. During the power transmission, the meter must be used effectively according to the relevant rules and regulations and the relevant management department should reduce the approval of electric energy meter to support the development of electric energy metering career.

\section{Conclusion}

All in all, the power resources is necessary to the normal operation of modern society and also an important factor of maintaining people's life and ensuring the economic development. The electric power production and transmission contain multiple departments and in this complex process, the improvement of the accuracy of electric energy metering involves various technical and economic problems. However, the economic benefits of electric power enterprises can be improved finally only by taking effective measures to reduce the error of various links, providing accurate metering data for power plant, power supply enterprises and users and ensuring the stable operation of power system.

\section{References}

[1] Liang Yang. Calculation of Comprehensive Error of Electric Energy Device[J]. Science and Technology Consulting Herald, 2012,(15):86.

[2] Huang Wentao, Ma Dongxue. Discussion on Method of Improving the Accuracy of HV Electric Energy Metering Device[J]. Electric Power of Henan, 2013,(01):89-90.

[3] Fan Xiaoying. Discussion on Method of Improving the Accuracy of Electric Energy Metering[J]. Technology Wind, 2013,(02):69-70.

[4] Zhuang Wangsheng. Discussion on Method of Reducing the Error of Electric Energy Metering[J]. Electrician Abstracts, 2013,(02):40-41. 